\title{
¿Cómo sobrevivir a la enseñanza del metabolismo celular en bachillerato?
}

\author{
Irma Sofía Salinas Hernández
}

\section{Resumen}

Dentro de los contenidos temáticos de la asignatura de Biología existen temas como el de metabolismo celular que didácticamente son difíciles de abordar en el aula y de comprender por los estudiantes debido a los conceptos y procesos que involucran. En este artículo se señalan los diferentes factores que intervienen y se brindan alternativas para el docente a fin de ayudar a mitigar los problemas de enseñanza y aprendizaje recurrentes en el aula.

Palabras clave: metabolismo celular, concepciones previas, estrategia didáctica, secuencia didáctica.

\section{HIGH SCHOOL STUDENTS' STRUGGLES WHILE UNDERSTANDING CELL METABOLISM}

\begin{abstract}
The Biology syllabus includes topics such as cell metabolism that represent a didactic challenge for both, teachers and high school students due to the complexity of the concepts and process the topic involves. This article shows different elements that intervene in the process and provides alternatives for teachers to reduce struggles with the teaching-learning strategies inside the classroom.
\end{abstract}

Keywords: cell metabolism, preconcepts, didactic strategy and didactic sequence. 


\section{Irma Sofía Salinas Hernández}

Profesora de Carrera de Tiempo Completo Titular "C", Definitiva adscrita a la Escuela Nacional Colegio de Ciencias y Humanidades (ENCCH) plantel Sur de la Universidad Nacional Autónoma de México (UnAm). Bióloga, con Doctorado en Ciencias Biológicas por la Facultad Ciencias de la Educación de la Universidad de Granada, España en donde obtuvo "Cum laude" (mención honorífica). Impartidora y diseñadora de diversos cursos de formación para profesores en la ENCCH. Cuenta con diversas publicaciones dentro de la ENCCH como lo es en el Portal Académico y en las revistas Eutopía y CONSCiencia; así como en la RUA y en memorias derivadas de diversos Simposios y Congresos sobre estrategias didácticas y el uso de las TIC y TAC, ambas enfocadas a los contenidos temáticos de las asignaturas de Biología. Coordinadora de diferentes grupos de trabajo institucionales de la ENCCH. Jurado en concursos abiertos para obtener plazas de definitividad para profesores de asignatura, así como para plazas de profesor de carrera de tiempo completo. Integrante del Consejo Académico del área de Ciencias Experimentales (CACE) durante dos periodos consecutivos (2013-2015 y 20162018). Asesora de alumnos en diversos eventos académicos dentro de la ENCCH, como la Olimpiada Universitaria del Conocimiento (ouc) Bachillerato y en el Concurso Universitario Feria de las Ciencias, la Tecnología y la Innovación, siendo ganadora en la xxvi emisión celebrada en 2018 del Tercer lugar en el área de Biología en la modalidad Investigación de campo. 


\section{Introducción}

La enseñanza y aprendizaje del metabolismo celular (fotosíntesis, respiración celular y fermentación) es uno de los contenidos temáticos más difíciles de abordar en el aula. Salinas y Serrano (2017, p. 56) señalan que "desde hace más de tres décadas las investigaciones educativas sobre el tema de fotosíntesis han puesto de manifiesto a nivel mundial la existencia de graves problemas de enseñanza aprendizaje especialmente a nivel de secundaria y de bachillerato". Más adelante, Salinas y Serrano (2019) comentan que algo similar ocurre con el tema de respiración celular donde la bibliografía consultada muestra "que las concepciones previas que presentan los alumnos de [estos dos niveles educativos] acerca de este tema se caracterizan por su universalidad" (p. 212).

Las razones de una realidad educativa con la que el docente se enfrenta cada vez que aborda este tema dentro de los programas de estudio son diversas. Algunas de ellas son "la forma en la que el profesor imparte su clase, [el] método de enseñanza empleado, [el] planteamiento didáctico utilizado, pero sobre todo el nivel de complejidad y profundidad del tema, el cual, en muchas ocasiones, no es proporcional con el nivel cognitivo de los alumnos que cursan los niveles educativos antes mencionados" (Salinas y Serrano, 2017, p. 56), especialmente cuando los conceptos y procesos que involucran son difíciles de comprender por los estudiantes (2019, p. 212).

A continuación, se muestra un resumen sobre los principales aspectos que influyen en la enseñanza y aprendizaje de los contenidos temáticos descritos con la finalidad de que el lector conozca o amplíe la información referente a dichos temas y algunas propuestas enfocadas al profesorado que trabaja, particularmente, en estos niveles educativos. Lo anterior podrá orientarlo en cómo reducir las dificultades que presentan los alumnos de bachillerato sobre el tema de metabolismos celular.

Durante cinco años escolares consecutivos(2011-2016)fue posible detectar, a través de un cuestionario de preguntas abiertas y de manera presencial, las concepciones previas referentes a dichos temas de un total de 250 alumnos que cursaron la asignatura de Biología i en el turno matutino correspondiente al tercer semestre de uno de los dos subsistemas de bachillerato que ofrece la Universidad Nacional Autónoma de México (UnAm), la Escuela Nacional Colegio de Ciencias y Humanidades (ENCCH) en el plantel sur.

Antes del pre-test aplicado al alumnado, se había diseñado y administrado examen piloto con el fin de reajustar las preguntas que conformarían el instrumento definitivo. Una vez teniendo todos los cuestionarios contestados se procedió, con base en las respuestas de los estudiantes, a la formación de diversas categorías para cada una de las preguntas abiertas. En cada clasificación se calculó el número de respuestas por grupo para cada ítem, la frecuencia absoluta de respuestas y el porcentaje de éstas. En el siguiente apartado se indican los resultados en porcentajes. 
Cuadro 1. Porcentaje obtenido de las concepciones previas de los alumnos encuestados durante los periodos 2011 2016 referentes al tema de fotosíntesis.

\section{Concepciones previas en los alumnos}

Los resultados obtenidos acerca de las concepciones previas que presenta el estudiantado encuestado de la ENCCH plantel sur sobre el tema de fotosíntesis se muestran en el cuadro 1.

\begin{tabular}{|l|c|}
\hline \multicolumn{1}{|c|}{ Concepciones previas referentes a fotosíntesis } & Porcentaje (\%) \\
\hline Nutrición de las plantas & 38.1 \\
\hline $\begin{array}{l}\text { Proceso por el cual las plantas absorben } \mathrm{CO}_{2} \text { y lo transforman en } \\
\mathrm{O}_{2}\end{array}$ & 32.9 \\
\hline Proceso por el cual las plantas respiran & 8.3 \\
\hline Transformación de la energía luminosa a energía química & 6 \\
\hline Integra todas las respuestas anteriores en una sola & 2 \\
\hline No contesta & 12.7 \\
\hline
\end{tabular}

Aunque la mayoría de las respuestas son correctas, se observa cómo los alumnos las consideran como procesos aislados, resultados que coinciden con los de Sáenz (2012, p. 36) quien señala que los estudiantes "perciben el proceso de fotosíntesis de manera fragmentada y no logran establecer [que dicho proceso] requiere de diversos factores, que en su conjunto son indispensables".

Al indagar por qué es importante la respiración celular solamente 3.0\% del alumnado mencionó que es debido a que le proporciona energía a la célula produciendo ATP y que se realiza en la mitocondria; sin embargo, esta respuesta sólo abarca a los organismos eucariontes dejando a un lado a los procariontes cuyo organelo involucrado es el citoplasma. El 45.6\% no contestó. El 51.4\% consideran a la respiración celular como el acto de inhalar $\mathrm{O}_{2}$ y exhalar $\mathrm{CO}_{2}$; es decir, la delimitan a nivel de organismo dejando a un lado la parte celular y entendiéndola como un intercambio de gases.

Estos resultados concuerdan con los de García (1991, p.131) y Charrier et al. (2006, p. 403) quienes encontraron que "para muchos estudiantes la respiración es sinónimo de intercambio gaseoso" aunado al hecho de que contemplan al humano "como el centro de la creación" (p. 404), ya que en ningún momento se refirieron a otro ser vivo que no fuera éste, como si asumieran que el hombre es el único ser vivo, lo que evidencia, tal y como lo señala Charrier et al. (2006, p. 404) "la imposibilidad que presentan los estudiantes de pensar en términos microscópicos". Esto resulta ser "un obstáculo para el aprendizaje ya que sólo [interpretan a la respiración] como un proceso macroscópico" (Quezada, 2011, citado por Farina 2013, p. 37) cuyo paso al nivel micro [como es el celular, mitocondrial y molecular] de acuerdo con Tamayo y Sanmartí (2003, p. 6) es "una de las más grandes dificultades a superar [por los estudiantes]". 
Cuadro 2. Porcentaje obtenido de las concepciones previas de los alumnos encuestados durante los periodos 2011 2016 referentes al tema de fermentación.
Los resultados obtenidos apoyan lo que afirman Charrier et al. (2006, p. 407) "existen serias dificultades para la construcción [de los conceptos de fotosíntesis y respiración y que además han venido a corroborar lo que los maestros [de diferentes países] han manifestado por años como fruto de sus observaciones empíricas: [la universalidad de] que tanto la fotosíntesis como la respiración son dos conceptos que por su complejidad resultan muy difíciles de ser enseñados y aprendidos".

Respecto al tema de fermentación, es notorio cómo la mayoría del alumnado desconoce a qué se refiere el proceso y solamente un pequeño porcentaje indica de manera aislada respuestas adecuadas (ver cuadro 2).

Concepciones previas referentes a fermentación Porcentaje (\%)

\begin{tabular}{|l|c|}
\hline No contesta & 61.4 \\
\hline Es la transformación de azúcares a bebidas alcohólicas y yogur & 12.5 \\
\hline Es cuando la comida o algo se echa a perder & 11.6 \\
\hline Proceso que realizan las bacterias y/o levaduras & 6 \\
\hline $\begin{array}{l}\text { Proceso de descomposición de azúcares provocado por bacterias } \\
\text { y/o hongos }\end{array}$ & 5 \\
\hline Proceso que no requiere de oxígeno & 3.5 \\
\hline
\end{tabular}

Estos resultados coinciden con los de Díaz et al. (1996, p. 145 y 146) quienes en su investigación encontraron que el estudiante "parece no tener ninguna idea concreta sobre el proceso de fermentación. Son alumnos que no contestan, o lo hacen con «no sé»". Asimismo, señalan que "entre los estudiantes que manifiestan alguna idea sobre fermentación, son muy pocos aquellos que lo hacen de forma correcta o siquiera próxima al concepto científico". De igual manera este autor (p. 145) declara que lo anterior es concebido para los alumnos "como un proceso intrínseco de la materia sin que intervengan seres vivos ni de dentro ni de fuera del alimento, y en el cual sólo el paso del tiempo parece ser tenido en cuenta como elemento importante".

\section{Factores que provocan la dificultad}

Ante esta situación surgen las siguientes cuestiones, ¿cuál es la causa de que se les dificulte a los alumnos temáticas en torno al metabolismo celular?, ¿por qué al indagar sus concepciones los resultados no son tan favorables como cuando se les cuestiona sobre ecología, por ejemplo?, ¿a qué se debe esta universalidad de concepciones? La respuesta es multicausal y es producto de una estrecha relación entre diferentes factores que a continuación resalto y que en su mayoría son considerados por diversos autores.

Charrier et al. señalan que algunas de las causas posibles son las concepciones disciplinarias que presentan los docentes tanto en preparación 
como en activo, los libros de texto consultados y empleados en clase y el desarrollo curricular de cada institución (2006, p. 407).

El origen y persistencia de las mismas concepciones que muestran los alumnos son otra variable. Entre ellas destacan, de acuerdo con Carrascosa (2005, p. 192, 194, 197 y 198) la influencia de las experiencias físicas cotidianas, la influencia de la comunicación verbal, visual y escrita, los libros de texto con graves errores conceptuales y la metodología utilizada en el proceso de enseñanza y aprendizaje. Para mayor detalle consultar la bibliografía referida.

Otro factor que influye en esta universalidad de concepciones es el nivel cognitivo que se requiere de los alumnos, entre 15 y 17 años, para abordar dichos temas de naturaleza compleja. No obstante, éste generalmente no está a la par del que presentan cuando cursan la asignatura de Biología ı. Dichas temáticas implican por parte del alumnado razonamientos e inferencias que adquieren a través del desarrollo de habilidades de pensamiento analítico, crítico, creativo y/o de resolución de problemas que favorezcan su propia construcción del conocimiento, mismas que en el estudiantado se encuentran en etapa de adquisición y formación.

Marco et al. (1987) indican que "los alumnos de 12-16 años tienen aún muchas dificultades con el tipo de razonamiento abstracto. Tienden a un razonamiento muy mediatizado por las percepciones sensoriales, por lo concreto y observable y consideran e interpretan los fenómenos desde un punto de vista antropocéntrico" (p.112). Esto ayuda a entender las concepciones previas de los alumnos de bachillerato encuestados, quienes antes de cursar la asignatura de Biología I, tuvieron su último contacto con la materia al cursar Ciencias 1, disciplina que se imparte en primer grado de secundaria cuando los alumnos tienen en promedio una edad de 11-12 años donde su forma de razonamiento se percibe simple, vertical, con una lógica cotidiana de su entorno.

Lo anterior se vincula con la "clasificación de los diferentes tipos de lenguaje" planteados en dos niveles por Galogovsky en 2004 y citado por Aguilar et al. en 2007:

El nivel macroscópico que corresponde a las representaciones mentales adquiridas a partir de la experiencia sensorial directa. Este nivel se construye mediante la información proveniente de los sentidos y el nivel simbólico, en él se ubican las interpretaciones del fenómeno. Este nivel involucra formas de expresión abstractas como fórmulas, ecuaciones, gráficos, definiciones (p. 694).

Bajo este tenor, el metabolismo celular se encuentra en un nivel simbólico donde para los diferentes organelos celulares y compuestos químicos involucrados como el citoplasma, el cloroplasto, la mitocondria, la clorofila, la glucosa, las enzimas, el ATP, el piruvato, el lactato, los transportadores de electrones, las bacterias no existen ejemplos directamente observables. 
Estos resultados permiten concluir que la apreciación microscópica no existe en el esquema mental del alumnado. Los jóvenes se guían por lo evidente y lo evidente tiene que ser de mediano y/o gran tamaño para que esté a su alcance y así sea perceptible y pueda ser considerado. Razones que se suman a la falta de interés y de motivación por parte de los estudiantes.

\section{Sugerencias y alternativas}

Una vez dadas las causas que originaron esta discusión, queda la pregunta que todo docente se realiza, ¿qué hacer ante esta situación? La respuesta radica, de acuerdo con la experiencia obtenida, básicamente en el diseño e implementación de estrategias y/o secuencias didácticas por parte del profesorado que se caractericen, no obligatoriamente, en este orden:

1. interés y motivación hacia el alumnado;

2. considerar los diferentes estilos de aprendizaje de los alumnos;

3. abarcar y vincular a la par los contenidos conceptuales, procedimentales y actitudinales inmersos en el currículo;

4. involucrar el aprendizaje cooperativo que "es una de las estrategias metodológicas que enfatizan en el hecho de que el alumno no aprende en solitario" (Moncada \& Gómez, 2012, p. 146). Sánchez (2012) menciona que "mientras más trabajan los estudiantes en grupos de aprendizaje cooperativo, aprenden más, entienden mejor lo que están aprendiendo, les es más fácil recordar lo que aprenden y se sienten mejor consigo mismos, con la clase y con sus compañeros" (p. 17);

Imagen 1. Trabajo cooperativo y aprendizaje autónomo fomentado entre los alumnos de la ENCCH plantel Sur.

[Fotografía de Irma Sofía Salinas Hernández]. (Laboratorio de Ciencias en la ENCCH Sur, CDMX, 2018).

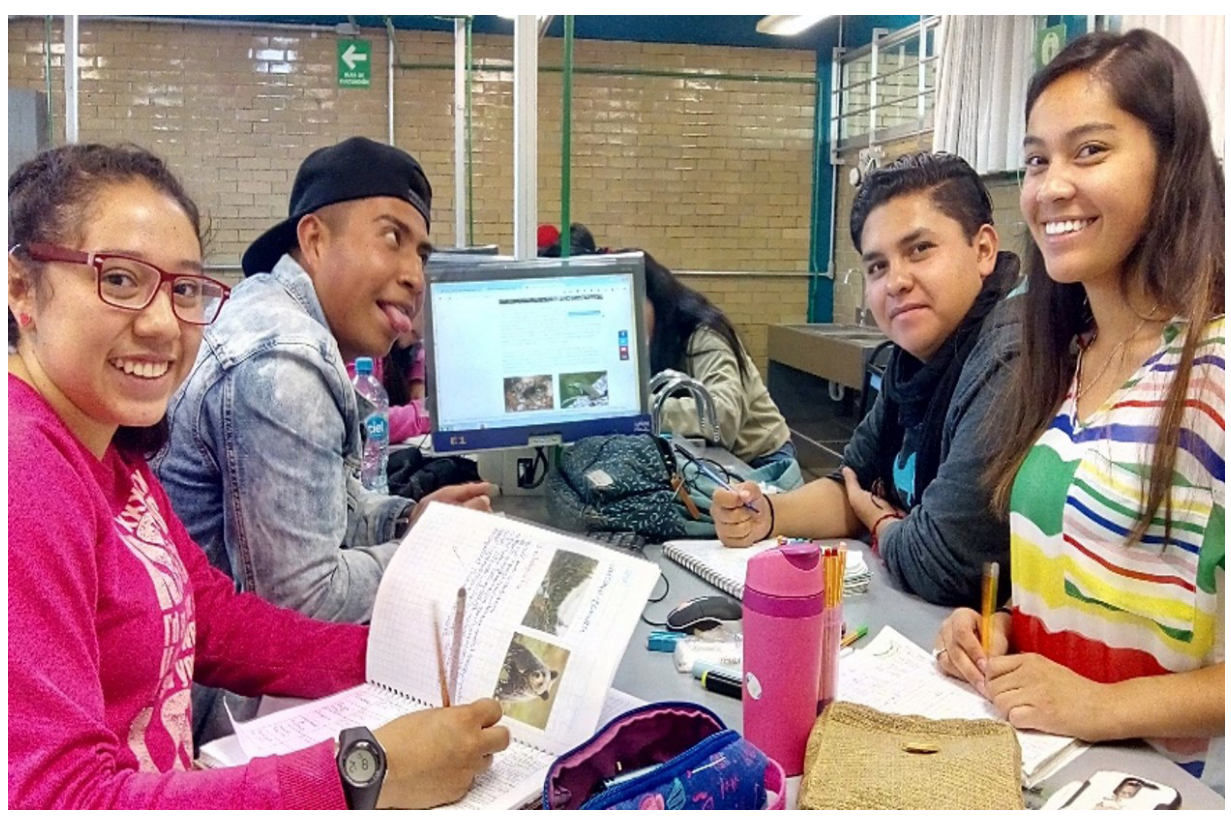


Imagen $\mathbf{2}$ Trabajo elaborado por una alumna donde muestra una analogía entre la respiración celular y tres diferentes heladerías.

[Fotografía de Irma Sofía Salinas Hernández]. (Laboratorio curricular en la ENCCH Sur, CDMX, 2015).

1"Una analogía es una comparación entre dos dominios de conocimiento que mantienen una cierta relación de semejanza entre sí. Se pretende que el alumno comprenda una determinada noción o fenómeno, que se denominan objeto o blanco, a través de las relaciones que establece con un sistema análogo, que se denomina ancla o fuente y que resulta para el alumno más conocido y familiar" (Aragón et al., 1999, p. 1).
5. introducir el aprendizaje autónomo, tal y como se observa en la imagen 1, definido por Chica (2010) como "una forma de aprender a educarse para la vida [...] a partir de la autogestión del conocimiento individual y el trabajo cooperativo" (p. 170);

6. Ios recursos didácticos empleados por el profesor como su participación directa en la forma en que imparte clase y el método de enseñanza empleado son variables a considerar, así como su compromiso ante el proceso de enseñanza y aprendizaje. Aunque es cierto "el estudiante sea el responsable de su propio aprendizaje" también hay que admitir que "el profesor es guía del proceso, quien plantea tareas que implican retos significativos para el joven con el propósito de generar en él estrategias creativas de aprendizaje y comprensión" (Moncada y Gómez, 2012, p. 65) y;

7. Ias actividades pueden ser novedosas, procurando no caer en aquellas consideradas como tradicionales a las que recurrimos los docentes, tales como cuestionarios y lecturas, entre otras. La experiencia obtenida me indica que deben ser creativas ya que permite el desarrollo de habilidades de pensamiento. Ejemplo de esto es el uso de analogías ${ }^{1}$ que actúa como una herramienta didáctica muy efectiva en el proceso de construcción de conocimientos, particularmente en temas como los aquí abordados debido a que se atienden "dominios abstractos, objetos y eventos que son muy difíciles de visualizar" (Charrier et al., 2006, p. 405-406) para jóvenes de este nivel educativo, cuyos contenidos son introducidos relativamente muy temprano hablando a nivel cognitivo.

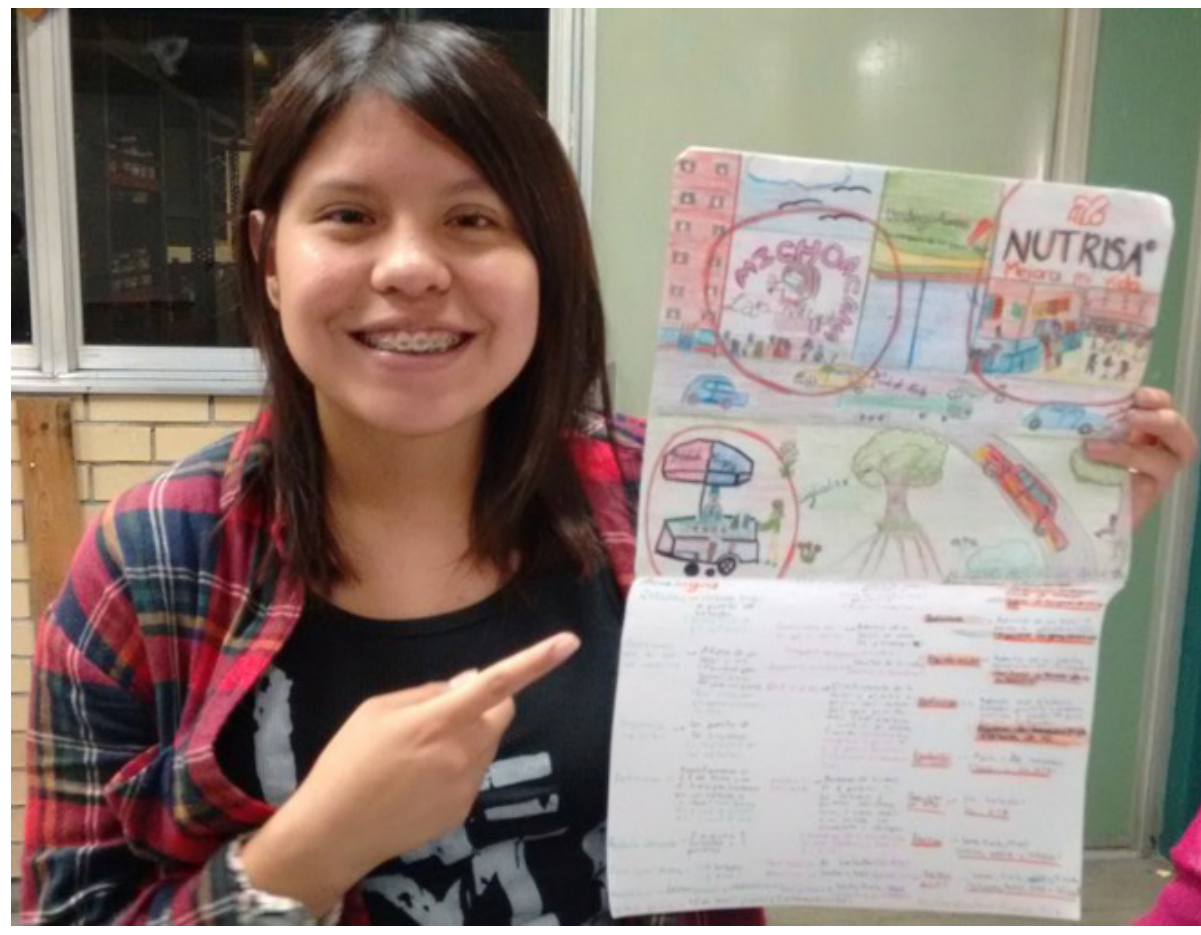


Por ejemplo, en la imagen 2 se muestra una analogía realizada por una alumna sobre el tema de respiración celular que integra los procesos metabólicos de glucolisis, ciclo de Krebs y cadena respiratoria comparándolos con tres diferentes heladerías (para mayor detalle consultar Salinas y Serrano, 2019). Farina (2013) recomienda su utilización "dada la dificultad de comprender la biología a nivel microscópico" (p. 39). De esta manera con el uso de analogías, "se fomentaría [...] la creatividad, la abstracción, la capacidad crítica y se desarrollaría la autonomía de los alumnos" (Aragón et al., 1999, p. 3).

\section{Conclusiones}

Tras la lectura de este artículo podemos concluir que el proceso de enseñanza y aprendizaje no se limita a que el profesor prepare sus clases, las imparta y evalúe el aprendizaje de sus alumnos, va más allá de esta ardua, cotidiana y, en ocasiones, monótona labor.

El docente puede, a partir de lo que sucede dentro y fuera del aula, ayudar a incidir en dicho proceso, especialmente cuando se trata de temas disciplinarios en los que, por lo general, el nivel cognitivo del alumno de bachillerato no coincide con los aprendizajes establecidos en los programas de estudio de las diversas instituciones educativas, como es el caso de la ENCCH. Para lograrlos, el académico tiene que adentrarse a contenidos temáticos que involucren conceptos, definiciones y procesos de cierta profundidad, complejidad, razonamiento y abstracción que el estudiantado aún no desarrolla por completo, impidiendo una absoluta comprensión y asimilación de dichos temas un tanto áridos e imperceptibles para ellos, como es el caso del tema al que se refiere este artículo.

Bajo esta perspectiva, la formación, la experiencia y la didáctica del profesorado serán herramientas clave en este proceso educativo, asimismo, ayudarán a disminuir las dificultades presentes en los alumnos de bachillerato sobre temas que, al igual que el de metabolismo celular, comparten las mismas características.

\section{Referencias}

* Aguilar, S., Maturano, C. \& Núñez, G. (2007). Utilización de imágenes para la detección de concepciones alternativas: un estudio exploratorio con estudiantes universitarios. Revista Electrónica de Enseñanza de las Ciencias, 6(3), 691-713. Recuperado de: http://reec.webs.uvigo.es/volumenes/volumen6/ART12 Vol6 N3.pdf.

* Aragón, M., Bonat, M., Oliva, J. \& Mateo, J. (1999). Las analogías como recurso didáctico en la enseñanza de las ciencias [versión electrónica]. Alambique, 21. 
* Carrascosa, J. (2005). El problema de las concepciones alternativas en la actualidad (Parte i). Análisis sobre las causas que la originan y/o la mantienen. Revista Eureka sobre Enseñanza y Divulgación de las Ciencias, 2(2), 183-208. Recuperado de: http:// www.redalyc.org/articulo.oa?id=92020206.

* Charrier, M., Cañal, P. \& Rodrigo, M. (2006). Las concepciones de los estudiantes sobre fotosíntesis y la respiración: Una revisión sobre la investigación didáctica en el campo de la enseñanza y el aprendizaje de la nutrición de las plantas. Enseñanza de las Ciencias, 24(3), 401-410.

* Chica, F. (2010). Factores de la enseñanza que favorecen el aprendizaje autónomo en torno a las actividades de aprendizaje. Reflexiones Tecnológicas, 6, 167-195.

* Díaz, R., López, R., García, A., Abuín, G., Nogueira, E. \& García, J. (1996). ¿Son los alumnos capaces de atribuir a los microorganismos algunas transformaciones de los alimentos? Enseñanza de las ciencias, 14(2), 143-153.

* Farina, J. (2013). Conceptos previos sobre respiración y función biológica del oxígeno en estudiantes ingresantes a la carrera de Psicología. Revista de Educación en Biología, 16(2), 31-40.

* García, M. (1991). Estudio llevado a cabo sobre representaciones de la respiración celular en los alumnos de bachillerato y cou. Enseñanza de las ciencias, 9(2): 129134.

* Marco, B., Olivares, E., Usabiaga, C., Serrano, T. \& Gutiérrez, R. (1987). La enseñanza de las Ciencias Experimentales. Etapa 12-16 años. Narcea.

* Moncada, C. \& Gómez, V. (2012). Tutorías en competencias para el aprendizaje autónomo. Trillas.

* Sáenz, J. (2012). La fotosíntesis, concepciones, ideas alternativas y analogías. Unidad didáctica dirigida a estudiantes de los ciclos 3 y 4 de educación básica del colegio José María Carbonell [tesis de maestría, Universidad Nacional de Colombia]. Recuperado de: http://www.bdigital.unal.edu.co/7577/1/jorgeenriquesaenzguarin.2012.pdf.

* Salinas, I. \& Serrano, M. (2017). Al estilo de la famosa tía clorofila. La receta secreta más buscada y menos entendida: generalidades de la fotosíntesis. En Memoria del $18^{\circ}$ Simposio de Estrategias Didácticas en el Aula (pp. 56-60). Escuela Nacional Colegio de Ciencias y Humanidades (encch) Plantel Sur, unam.

* Salinas, I. \& Serrano, M. (2019). Estrategia didáctica en apoyo al tema respiración celular. En Memoria del $5^{\circ}$ Congreso y $20^{\circ}$ Simposio de Estrategias Didácticas en el Aula (pp. 212-218). Escuela Nacional Colegio de Ciencias y Humanidades (encch) Plantel Sur, unam.

- Sánchez, M. (2013). Estrategias didácticas para Bachillerato y nivel Superior. Trillas.

* Tamayo, O. \& Sanmartí, P. (2003). Estudio Multidimencional de las Representaciones Mentales de los Estudiantes. Aplicación al Concepto de Respiración. Revista Latinoamericana de Ciencias Sociales, Niñez y Juventud, 1(1), 1-16. Recuperado de: doi: $\quad$ http://www.scielo.org.co/scielo.php?script=sci arttext\&pid=S1692$\underline{715 \times 2003000100007}$ 


\section{Cómo citar este artículo}

* Salinas Hernández, Irma Sofía (2020). ¿Cómo sobrevivir a la enseñanza del metabolismo celular en bachillerato? Revista Digital Universitaria (RDU). Vol. 21, núm. 2 marzo-abril. Dol: http://doi.org/10.22201/codeic.16076079e.2020.v21n2.a8.

Recepción: 18/05/2018. Aprobación: 12/11/2019 